\title{
Novel UV filters from Pentacalia pulchella extracts with photoprotective properties and antioxidant activity
}

\author{
Juan C. Mejía-Giraldo ${ }^{1,2}\left(\right.$ Robert $^{-}$Winkler $^{3}\left(\mathbb{D} \cdot\right.$ Miguel Puertas-Mejía $^{1}(\mathbb{C}$
}

Received: 9 June 2021 / Accepted: 18 October 2021 / Published online: 1 November 2021

(c) The Author(s), under exclusive licence to European Photochemistry Association, European Society for Photobiology 2021

\begin{abstract}
Most of the plant species found in the high mountain ecosystems of the tropics is unique and exceptional, because they have developed complex adaptations to survive in extreme environmental conditions, such as high levels of UVR and low temperatures of these ecological environments. In an exploratory study carried out on some plants of this ecosystem, we found that one of the most promising species was the Pentacalia pulchella (Kunth) Cuatrec. (Asteraceae) an endemic plant of Colombia, which grows between 2500 and 3500 m.a.s.l. Therefore, the objective of this work was to evaluate the photoprotective, antioxidant, and chemical composition of extracts from the leaves of $P$. pulchella. Extracts showed good absorption coefficients in UVA-UVB, high content of total phenols, with antioxidant activity comparable to that obtained with butylhydroxytoluene (BHT). Finally, the formulation labeled "7" with 10\% extract presented adequate sensory characteristics for topical use, good in vitro photoprotection values in the UVA-UVB range (SPF (Sun Protection Factor): 7.3 \pm 0.9 , UVAPF (Ultraviolet A Protection Factor): $5.3 \pm 0.6, \lambda_{\mathrm{c}} 376$ ), and antioxidant activity. Results obtained allow us to suggest that the extract of $P$. pulchella has a high potential as a source of new natural solar filters.
\end{abstract}

Keywords Natural sunscreens $\cdot$ Pentacalia pulchella $\cdot$ Photoprotection $\cdot$ UVA-UVB radiation

\section{Introducción}

In recent decades, a notable increase in the incidence of skin cancer has been observed around the world, which is mainly associated with habits of excessive exposure to ultraviolet radiation (UVR) from the sun [1-3]. In small doses, UVR is beneficial for health since they favor the production of vitamin D. However, overexposure can cause erythema, sunburn, carcinomas, cataracts, and other eye diseases, as well as photo-aging. Additionally, it has been proven that these

Juan C. Mejía-Giraldo

juan.mejia8@udea.edu.co

1 Grupo de Investigación en Compuestos Funcionales, Facultad de Ciencias Exactas y Naturales, Universidad de Antioquia UdeA, Calle 70 No. 52-21, Medellín, Colombia

2 Grupo de estabilidad de medicamentos, cosméticos y alimentos, Facultad de Ciencias Farmacéuticas y Alimentarias, Universidad de Antioquia UdeA, Carrera 50A No 63-85, Medellín, Colombia

3 Departamento de Biotecnología y Bioquímica-CINVESTAV, Libramiento Norte Carretera Irapuato León Kilómetro 9.6, Irapuato Gto., 36824 Irapuato, México radiations reduce the immune system's efficiency, since they modify the activity and distribution of cells responsible for the immune response [2, 4-7].

Likewise, solar radiation has a dual effect on plants; it can be beneficial and harmful. For this reason, environmental conditions have a great influence on the morphology and physiology of plants, since characteristics, such as size and shape, are modified by light, temperature, and drought, among others. These environmental conditions also modify its metabolism, leading to a decrease or increase of secondary metabolites [8-12]. One of the defense mechanisms identified against UVR damage is the production of polyphenolic compounds, among which the most characterized group are flavonoids. At present, numerous studies have helped understand not only their biosynthesis but also the metabolomic and genetic expression factors necessary for the biosynthesis of these molecules [12-15]. Studies have also been carried out that correlate the increased production of flavonoids when the plant is under environmental stress conditions. Then, high levels of UVR, low temperatures, pollution, and droughts can induce oxidative stress, which produces an increase in reactive oxygen species (ROS), generating alarm signaling processes in plants. Thus, they 
modify metabolism and gene expression, to respond to adverse environmental conditions $[9,11,12,15,16]$.

In this sense, raw materials of natural origin could be a new source of bioactive compounds for skin sun protection. Numerous approaches and studies have been directed at groups of secondary metabolites, looking for photoprotective properties. Thus, compounds, such as carotenoids, mycosporins, and polyphenols, have been studied, obtaining promising results [17-20]. Regarding polyphenols, there is broad evidence in the literature of the benefits that these compounds can have when used as adjuvants in photoprotective formulations [11, 12, 21-26]. The additional advantages of polyphenols, when they are used as photoprotective bioactive, are as follows: their wide distribution in the plants that allows their easy availability, and their antioxidant potential that decreases the damage by oxidative stress induced by UVR [23, 27-29].

Furthermore, various polyphenols, such as epigallocatechin, resveratrol, caffeic acid, ferulic acid, quercetin, and kaempferol, among others, have also been found to have the ability to act as broad-spectrum sun filters, covering the UVA-UVB radiation range $[11,12,30]$. This evidence allows us to infer those polyphenols are promising compounds that could be used as new sun protection strategies. Colombia is a mega-diverse country, and new sources of photoprotection can be suspected in the plants of high mountain ecosystems. Therefore, we evaluated the chemical composition and photoprotective and antioxidant properties of the high-altitude plant Pentacalia pulchella (Kunth) Cuatrec. (Asteraceae).

\section{Materials and methods}

\subsection{Chemicals}

2,2-Diphenyl-2-picrylhydrazyl (DPPH•), polysorbate 80, gallic acid, and reference standards for LC and MS testing (caffeic acid, 3,4-dimethoxycinnamic acid, chlorogenic acid, ferulic acid, rutin, quercetin, and kaempferol) were obtained from Sigma Chemical Co. (St. Louis, MO). 2-thiobarbituric acid (TBA), butylated hydroxytoluene (BHT), and methyl linoleate (MeLo) were provided from Alfa Aesar (Ward Hill, MA, USA). Formic acid was obtained from Fermont (Monterrey, NL, México). Folin-Ciocalteu phenol reagent, methanol-HPLC, acetone, 37\% hydrochloric acid, potassium chloride, sodium acetate, and sodium carbonate were obtained from Merck Chemical Supplies (Darmstadt, Germany). Carbomer 940 (Carbopol 940), triethanolamine (TEA), propylene glycol, and glycerin were obtained from LM. Productos químicos (Medellín, Colombia). All reagents were used as received.

\subsection{Collection and extraction of plant material}

The plant material (leaves) was collected in July 2013 in the municipality of Yarumal (Llanos de Cuiva), AntioquiaColombia, $\left(6^{\circ} 49^{\prime} 50.6^{\prime \prime} \mathrm{N} ; 75^{\circ} 29^{\prime} 29.9^{\prime \prime} \mathrm{W}\right)$ at 2730 m.a.s.l. A specimen was deposited in the Herbarium of the University of Antioquia, Medellín, Antioquia, Colombia with voucher number HUA194797. Contract for Access to Genetic Resources and their Derivative Products $N^{\circ} 252$, Resolution 0399-Ministerio de Ambiente y Desarrollo Sostenible, Colombia. The leaves were dried at room temperature for 30 days protected from light. Then, dry vegetal material (DVM) was minced using an electric mill (IKA, A11 basic S1). Briefly, $1 \mathrm{~g}$ of crushed DVM was degreased using $50 \mathrm{~mL}$ of hexane and magnetic stirring for $6 \mathrm{~h}$ ( $c a$. $25 \pm 2{ }^{\circ} \mathrm{C}$ ). Next, the defatted DVM was subjected to extraction with $50 \mathrm{~mL}$ of solvent (methanol or acetone) and hydrochloric acid $37 \%(\mathrm{v} / \mathrm{v})(0$ or $0.25 \mathrm{~mL})$ at room temperature (ca. $25 \pm 2{ }^{\circ} \mathrm{C}$ ) with magnetic stirring for $24 \mathrm{~h}$. Then, the extracts were filtered and treated with activated carbon $(0$ or $1 \mathrm{~g})$ to remove chlorophylls, filtered again through paper filters, and $0.45 \mu \mathrm{m}$ membranes and dried on a rotary evaporator (IKA RV10 Basic, $40^{\circ} \mathrm{C}$ ). Finally, the dry extracts were dissolved in $100.0 \mathrm{~mL}$ of methanol and stored at $-9^{\circ} \mathrm{C}$. All assays were performed according to a full factorial design $\left(2^{3}\right)$. Each assay was performed in triplicate (Table 1).

\subsection{HPLC-DAD analysis}

Analysis of the main components present in each of the extracts was carried out on an Agilent Technologies 1200 Series HPLC (Agilent, Palo Alto, CA, USA), equipped with a diode array detector (G1315B DAD), a degasser (G1379B), a binary gradient pump (G1312A), an autosampler (G1367B), and a column thermostat (G1316A). Reverse phase separation was performed on a Symmetry ${ }^{\circledR}$ column

Table 1 Extraction conditions according to a full factorial design $\left(2^{3}\right)$

\begin{tabular}{llll}
\hline Assay & Solvent & $\mathrm{HCl}^{\mathrm{a}}$ volume, & $\begin{array}{l}\text { Acti- } \\
\text { vated } \\
\text { carbon }\end{array}$ \\
\hline 1 & Acetone & $0.25 \mathrm{~mL}$ & $0 \mathrm{~g}$ \\
2 & Acetone & $0.25 \mathrm{~mL}$ & $1 \mathrm{~g}$ \\
3 & Methanol & $0.25 \mathrm{~mL}$ & $0 \mathrm{~g}$ \\
4 & Methanol & $0.25 \mathrm{~mL}$ & $1 \mathrm{~g}$ \\
5 & Acetone & $0.00 \mathrm{~mL}$ & $0 \mathrm{~g}$ \\
6 & Acetone & $0.00 \mathrm{~mL}$ & $1 \mathrm{~g}$ \\
7 & Methanol & $0.00 \mathrm{~mL}$ & $0 \mathrm{~g}$ \\
8 & Methanol & $0.00 \mathrm{~mL}$ & $1 \mathrm{~g}$ \\
\hline
\end{tabular}

${ }^{\mathrm{a}} \mathrm{HCl}$ : hydrochloric acid $37 \%(\mathrm{v} / \mathrm{v})$ 
of $4.6 \mathrm{~mm} \times 75 \mathrm{~mm}$, particle size $3.5 \mu \mathrm{m}$ (Waters, Ireland) at constant temperature $\left(30^{\circ} \mathrm{C}\right)$, and a flow rate of $0.5 \mathrm{~mL} /$ min. For the separation, an elution gradient was used with a mobile phase composed of (A) formic acid $0.1 \%$ in Milli-Q water (v/v) and (B) formic acid in methanol HPLC grade $0.1 \%(\mathrm{v} / \mathrm{v})$. Gradient program was 30\% B (0.5 min), 30-90\% B (6.5 min), 90\% B (1 min), 90-30\% B (1 min), and 30\% B ( $2 \mathrm{~min}$ ). The injection volume was $2 \mu \mathrm{L}$. Chromatographic analysis was monitored at 290,310, 340, 380, and $520 \mathrm{~nm}$, and the diode array detector was set in an acquisition range, at wavelengths comprised between 190 and $700 \mathrm{~nm}$. Compounds were identified by their spectroscopic characteristics, such as absorption maxima, fragmentation patterns, and where possible by retention times compared to reference standards (caffeic acid, 3,4-dimethoxycinnamic acid, chlorogenic acid, ferulic acid, rutin, quercetin, and kaempferol).

\subsection{UPLC-ESI-IT-MS ${ }^{n}$ analysis}

Analysis of the main components present in each of the extracts was performed on a Thermo Scientific chromatograph equipped with an Accela autosampler and an Accela 600 quaternary pump coupled in-line to an LCQ Fleet ion trap mass spectrometer (Thermo Scientific). Reversed phase separation was performed as described in Sect. 2.3 and the injection volume was $10 \mu \mathrm{L}$. Effluent from the column was analyzed by ESI-MS in positive ion mode (LCQ Fleet ion trap from Thermo Scientific). The capillary voltage was set to $35 \mathrm{~V}$, spray voltage was $4.5 \mathrm{kV}$, and tube lens at $80 \mathrm{~V}$, Sheath Gas (nitrogen) flux was 45 (arbitrary units), and Aux Gas was 5 (arbitrary units). The capillary temperature was $300{ }^{\circ} \mathrm{C}$. Data were acquired in a mass range of $100-1000 \mathrm{~m} / \mathrm{z} . \mathrm{MS}^{\mathrm{n}}$ experiments were performed in the "Data Dependent Ion Tree" mode with a normalized collision energy of 35 (arbitrary units). Finally, data were analyzed using Xcalibur 2.1 (Thermo Scientific) and MZmine 2 (MZmine Development Team) software. Compounds were identified by their spectroscopic characteristics, such as molecular weight, fragmentation patterns, and where possible by comparison to reference standards (caffeic acid, 3,4-dimethoxycinnamic acid, chlorogenic acid, ferulic acid, rutin, quercetin, and kaempferol).

\subsection{Antiradical capacity-DPPH assay}

The antiradical ability of all extracts was determined using the DPPH• test as free radical [31, 32]. For each extract, different concentrations were evaluated, and the radical scavenging activity was calculated. The decrease in absorbance was determined at $515 \mathrm{~nm}$ at 0 min and every $30 \mathrm{~s}$ until completing $30 \mathrm{~min}$. The initial concentration of $\mathrm{DPPH} \bullet$ in the reaction medium was calculated from a calibration curve of DPPH measured at $515 \mathrm{~nm}$, in concentrations of 2.5, 5.0, $7.5,10,25,50$, and $100 \mu \mathrm{M}$ in methanol, prepared from the stock solution of $100 \mu \mathrm{M}$ (equation $y=1.146 \mathrm{E} 2 x-4.192 \mathrm{E}$ $3, r=0.9999)$. Antiradical activity was expressed as effective concentration $\left(\mathrm{EC}_{50}=\right.$ steady-state test concentration/DPPH concentration $=\mathrm{t} 0$ ). The results were compared against the antiradical activity of BHT.

\subsection{Antioxidant activity-lipid (MeLo) model}

The antioxidant capacity was measured by the inhibition of lipid peroxidation in MeLo, through the production of conjugated diene hydroperoxide (CDH) and thiobarbituric acid reactive substances (TBARS), using the method described by Mejía-Giraldo et al. [33]. Solutions of MeLo $10 \mathrm{mM}$ (negative control), MeLo plus BHT 0.02\% w/v (positive control), and MeLo plus $0.02 \%$ (w/v) of each extract were exposed to accelerated oxidation by heating at $40 \pm 5{ }^{\circ} \mathrm{C}$ for 5 days in test tubes. After accelerated oxidation, each sample was dissolved in $1 \mathrm{~mL}$ of ethanol. To quantify the concentration of $\mathrm{CDH}$ produced during oxidation, the samples were diluted with ethanol in a ratio of $1: 25$ and measured spectrophotometrically at $234 \mathrm{~nm}$, using an extinction coefficient of $29,000 \mathrm{M}^{-1} \mathrm{~cm}^{-1}$. The peroxidation level was expressed as $\mathrm{mmol} \mathrm{CDH} \mathrm{kg}{ }^{-1} \mathrm{MeLo}$. Also, the lipid peroxidation level was determined as TBARS and expressed as mmol malondialdehyde $\mathrm{kg}^{-1} \mathrm{MeLo}$ ( $\mathrm{mmol} \mathrm{MD} \mathrm{kg}{ }^{-1} \mathrm{MeLo}$ ) produced in the oxidation. For the quantification of TBARS, briefly, 50 $\mu \mathrm{L}$ of each sample was mixed with $350 \mu \mathrm{L}$ of ethanol, 100 $\mu \mathrm{L}$ of BHT $0.2 \%(\mathrm{w} / \mathrm{v})$ in ethanol, and $500 \mu \mathrm{L}$ of TBA $0.37 \%$ $(\mathrm{w} / \mathrm{v})$ in $\mathrm{HCl}(0.25 \mathrm{mM})$ in a test tube. The resulting mixture was heated for $30 \mathrm{~min}$ in a sand bath at $90 \pm 5{ }^{\circ} \mathrm{C}$ (the temperature of the sand bath was controlled using a temperature probe). The solution was rapidly cooled in an ice bath and the flocculated material was precipitated by centrifugation at $3000 \mathrm{rpm}$ for $10 \mathrm{~min}$. The absorbance of the samples was measured at $535 \mathrm{~nm}$ and corrected for non-specific turbidity by subtracting the absorbance at $600 \mathrm{~nm}$. Finally, the peroxidation level was expressed as mmol of malondialdehyde (MDA) per kg MeLo using a molar extinction coefficient of $156,000 \mathrm{M}^{-1} \mathrm{~cm}^{-1}$.

\subsection{Total phenolic contents: Folin-Ciocalteu assay}

The total phenolic contents (TPC) in all extracts were measured using the modified Folin-Ciocalteu colorimetric method [34, 35]. Briefly, $100 \mu \mathrm{L}$ of extract solution and 525 $\mu \mathrm{L}$ of deionized water were added to a test tube. Then, 125 $\mu \mathrm{L}$ of Folin-Ciocalteu reagent was added to the solution and it was allowed to react for $5 \mathrm{~min}$. Subsequently, 1250 
$\mu \mathrm{L}$ of $20 \%$ sodium carbonate solution was added and mixed. The blue color developed for $90 \mathrm{~min}$, and the absorbance was read at $760 \mathrm{~nm}$. TPC was calculated from a gallic acid calibration curve prepared at concentrations of $0,1,2,4,6$, 8 , and $10 \mathrm{mg} / \mathrm{L}$ in water, from a stock solution of $100 \mathrm{mg} / \mathrm{L}$, and expressed as milligrams of gallic acid equivalents (EAG) per gram of dry extract $(y=0.124 x+1.581 \mathrm{E}-2, r=0.9997)$.

\subsection{UVA-UVB absorption coefficient}

Appropriate dilutions of each extract were made with methanol. Subsequently, the absorption spectrum was carried out in the UV-visible (200-700 nm), in a quartz cuvette $(1 \mathrm{~cm}$ step length) for each extract. The absorption coefficients (absorbance $(\mathrm{A}) /(\mathrm{mg}$ of dry extract $/ \mathrm{mL})$ ) were calculated at 290, 310, 340, and $380 \mathrm{~nm}[35,36]$. All spectrophotometric measurements were acquired using a Thermo Scientific Evolution 60S UV-visible spectrophotometer.

\subsection{Preparation of sunscreen gel}

For evaluating the photoprotection and photostability of the extract, eight gel photoprotector formulations were prepared with each of the extracts from assays $1-8$, and were named in the same way as assays $1-8$. The extracts of $P$. pulchella were brought to dryness, in a rotary evaporator, with reduced pressure, until constant weight, to ensure the removal of the extraction solvent, and redissolved in a mixture of ethanol-propylene glycol-water (40:30:30), for a final concentration of $50 \%(\mathrm{w} / \mathrm{w})$. Then, the solution was incorporated into a gel formulation [carbomer $940(2.0 \%(\mathrm{w} / \mathrm{w})$ ], triethanolamine $[2.0 \%(\mathrm{w} / \mathrm{w})]$, glycerin $[2.0 \%(\mathrm{w} / \mathrm{w})]$, polysorbate $80[0.5 \%(\mathrm{w} / \mathrm{w})]$, and distilled water quantity sufficient (qs) $100)$, for a final concentration of $10 \%(w / w)$ of dry extract.
UV-2000S, Labsphere, North Sutton, USA). In vitro photoprotection efficiency in UVB was evaluated according to SPF (Sun Protection Factor) parameter and in vitro photoprotection efficiency in UVA according to UVAPF (Ultraviolet A Protection Factor), critical wavelength $\left(\lambda_{\mathrm{c}}\right)$, and the UVA/UVB parameters. All the calculations were performed according to the models proposed by ISO 24443 (2012) Determination of sunscreen UVA photoprotection in vitro [37]. For each assay, three plates were prepared and nine measurements were taken for each plate. As a blank, the gel without extract was used and a commercial sunscreen SPF 25 was evaluated as a positive control [37-39].

\subsection{Photostability of sunscreens}

The photostability of the sunscreen gel was evaluated using the method described by Jarzycka et al. [37-42]. Plates previously prepared (see above Sect. 2.10) were irradiated for $2 \mathrm{~h}$ with a solar simulator apparatus (Solarbox 1500e; Erichsen, Germany) equipped with a xenon arc lamp $(1500 \mathrm{~W})$ and special UV glass filters cutting off radiation below $290 \mathrm{~nm}$. The light source emission was maintained at $650 \mathrm{~W} / \mathrm{m}^{2}$ in accordance with global solar spectral irradiance. SPF, $\lambda_{\mathrm{c}}$, and UVA/UVB ratio parameters were measured at time zero and every $30 \min$ for $2 \mathrm{~h}$, and the UVAPF was measured at time zero and at $2 \mathrm{~h}$. The degree of photostability was expressed as the percentage of effectiveness, after exposure, of both protection factors: the SPF in vitro (\% SPF $\left.{ }_{\text {eff }}\right)$ and the UVA-PF (\% UVAPF $\left.{ }_{\text {eff }}\right)$, and calculated according to Eqs. (1) and (2), respectively. Three plates were prepared, and measurements were made nine times for each plate.

$\% \mathrm{SPF}_{\text {eff }}=\mathrm{SPF}_{\text {in vitro }}$ after irradiation $/ \mathrm{SPF}_{\text {in vitro }}$ before irradiation $* 100$,

$\% \mathrm{UVAPF}_{\text {eff }}=\mathrm{UVAPF}_{\text {in vitro }}$ after irradiation $/ \mathrm{UVAPF}_{\text {in vitro }}$ before irradiation $* 100$.

\subsection{In vitro determination of photoprotective efficacy}

Sunscreen gel was accurately applied $\left(0.75 \mathrm{mg} / \mathrm{cm}^{2}\right)$ to roughen polymethyl methacrylate (PMMA) plates (Helioplate HD6, Labsphere, Inc. North Sutton, NH, USA) spreading evenly over the entire surface with a gloved finger. The film was allowed to stabilize protected from light at room temperature $\left(\mathrm{ca} .25 \pm 2{ }^{\circ} \mathrm{C}\right)$ for $15 \mathrm{~min}$. UV diffuse transmittance measurements (290-400 nm) were performed with a spectrophotometer equipped with an integrating sphere (UV Transmittance Analyzer

\subsection{Sensory analysis}

Gel formulations were evaluated for the attributes of color, odor, appearance, and texture by three individually selected sensory evaluators. The gel samples were spread on white paper sheets and evaluated under white light. Descriptive and acceptance analysis of each of the attributes described was carried out, under the criteria of acceptability of a cosmetic product. In the evaluation of the appearance and texture, all the mechanical, geometric, and surface attributes of the formulations, perceptible through touch and vision, were evaluated [43, 44]. 


\subsection{Statistical analyses}

The results are expressed as the means $\pm \mathrm{SD}$. All data were analyzed by one-way or three-way analysis of variance (ANOVA) followed by Tukey tests when appropriate using R Development Core Team (2011), R: A Language and Environment for Statistical Computing and Microsoft Excel. $p$ values of less than $0.05(p<0.05)$ were considered significant.
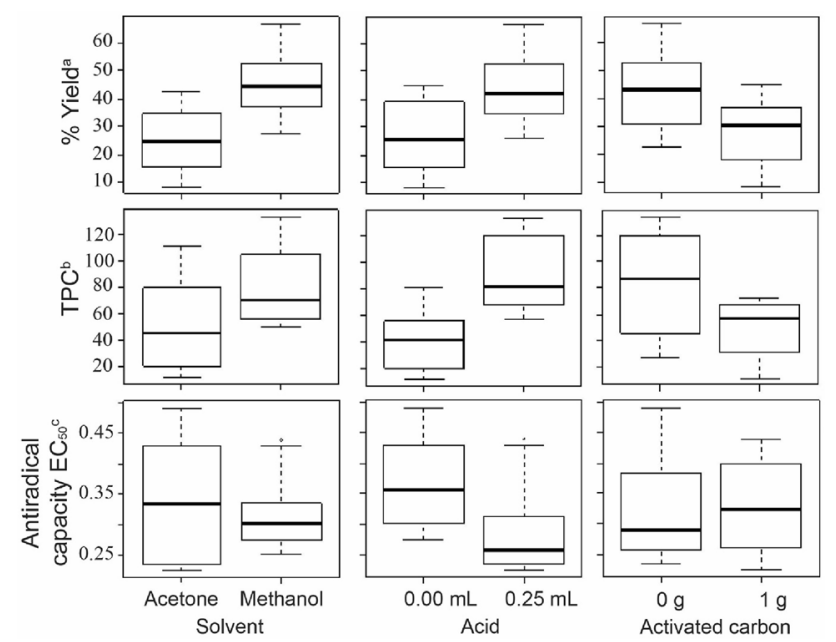

Fig. 1 Main effects of solvent, acid, and activated carbon on extraction effectiveness. ${ }^{\mathrm{a}} \%$ Yield extraction (\% dry extract), ${ }^{\mathrm{b}} \mathrm{TPC}$ : Total phenolic content (mg gallic acid equivalents per g dry extract). ${ }^{c} \mathrm{EC}_{50}$ : Efficient concentration 50 (g dry extract per mmol DPPH•)

\section{Results and discussion}

According to the analysis of variance of three factors, we found a significant effect was found in the triple interaction (solvent: acid: carbon; $p=0.04$ ) for the yield percentage. Figure 1 shows the global effect of solvent, acid, and activated carbon on the response variables of yield percentage, TPC, and antiradical capacity. According to the results, it was observed that methanol and the addition of acid increased the overall yield percentage of the extracts, and the addition of activated carbon decreased it. The assays with acidified methanol (tests 3 and 4) and the assays without acidification (tests 7 and 8) presented the highest yields. In addition, the treatment with activated carbon (assays 2, 4, 6 , and 8) significantly decreased the yield percentage, which was much more noticeable in assay $6(9.06 \pm 0.39 \%$ of dry extract) (Table 2). This shows that the carbon is adsorbing chlorophylls and other types of compounds, and it was observed with the change in color of the extract solutions.

Regarding the antioxidant capacity measured by the DPPH• free radical method and the inhibition of lipid peroxidation in MeLo by the extracts, we observed a significant effect of the three evaluated factors (solvent: acid: carbon; $p<0.05)$. Assays 4,5 , and 6 presented the highest $\mathrm{EC}_{50}$ values $(0.41 \pm 0.05,0.46 \pm 0.03$, and $0.40 \pm 0.0 \mathrm{~g}$ of dry extract/ $\mathrm{mmol} \mathrm{DPPH}$, respectively), while the $\mathrm{EC}_{50}$ values for assays $1,2,3$, and 8 were the lowest values $(0.2-0.3 \mathrm{~g}$ dry extract/ $\mathrm{mmol} \mathrm{DPPH})$, and did not present a statistically significant difference between them $(p>0.05)$. Although these values present a statistically significant difference with respect to
Table 2 Extraction yield, in vitro antioxidant capacity, and TPC of $P$. pulchella extracts

\begin{tabular}{llllll}
\hline & \% Yield & $\mathrm{TPC}^{\ddagger}$ & $\mathrm{EC}_{50}^{\dagger}$ & $\mathrm{CDH}^{\mathrm{T}}$ & $\mathrm{MDA}^{\ddagger}$ \\
\hline Assay 1 & $40.87 \pm 2.43 \mathrm{a}$ & $246.86 \pm 14.24 \mathrm{a}$ & $0.25 \pm 0.02 \mathrm{a}$ & $\mathrm{ND}$ & $0.58 \pm 0.03 \mathrm{a}, \mathrm{b}$ \\
Assay 2 & $29.43 \pm 2.83 \mathrm{~b}$ & $217.50 \pm 2.44 \mathrm{a}$ & $0.23 \pm 0.01 \mathrm{a}$ & $\mathrm{ND}$ & $0.35 \pm 0.08 \mathrm{a}$ \\
Assay 3 & $62.80 \pm 3.46$ & $210.52 \pm 15.84 \mathrm{a}, \mathrm{b}$ & $0.26 \pm 0.01 \mathrm{a}, \mathrm{b}$ & $\mathrm{ND}$ & $0.35 \pm 0.05 \mathrm{a}$ \\
Assay 4 & $42.73 \pm 2.74 \mathrm{a}$ & $161.83 \pm 16.64 \mathrm{c}$ & $0.41 \pm 0.05 \mathrm{c}, \mathrm{d}$ & $\mathrm{ND}$ & $1.44 \pm 0.25 \mathrm{c}$ \\
Assay 5 & $22.84 \pm 0.53$ & $133.52 \pm 16.58 \mathrm{c}$ & $0.46 \pm 0.03 \mathrm{c}$ & $\mathrm{ND}$ & $0.63 \pm 0.11 \mathrm{a}, \mathrm{b}$ \\
Assay 6 & $9.06 \pm 0.39$ & $132.88 \pm 9.35 \mathrm{c}$ & $0.40 \pm 0.01 \mathrm{~d}$ & $\mathrm{ND}$ & $1.17 \pm 0.13 \mathrm{~b}, \mathrm{c}$ \\
Assay 7 & $44.51 \pm 0.31 \mathrm{a}$ & $159.10 \pm 28.48 \mathrm{c}$ & $0.31 \pm 0.01 \mathrm{~b}$ & $\mathrm{ND}$ & $0.74 \pm 0.22 \mathrm{a}, \mathrm{b}$ \\
Assay 8 & $30.52 \pm 3.10 \mathrm{~b}$ & $171.39 \pm 7.80 \mathrm{~b}, \mathrm{c}$ & $0.29 \pm 0.01 \mathrm{a}, \mathrm{b}$ & $\mathrm{ND}$ & $1.10 \pm 0.23 \mathrm{~b}, \mathrm{c}$ \\
BHT* & - & - & $0.11 \pm 0.01^{\ddagger}$ & $\mathrm{ND}$ & $0.31 \pm 0.04 \mathrm{a}$ \\
MeLo* & - & - & - & $11.74 \pm 2.73$ & $10.22 \pm 0.48$ \\
\hline
\end{tabular}

Results are expressed as the mean value \pm standard deviation $(n=3)$. Values in the same column followed by different letters are significantly different at the 5\% level. BHTButylated hydroxytoluene, MeLo Methyl linoleate, $N D$ No detect. ${ }^{¥} \mathrm{TPC}$ : total phenolic content, $\mathrm{mg}$ gallic equivalents per g dry extract. ${ }^{\dagger} \mathrm{EC}_{50}$ : efficient concentration 50, g dry extract per mmol DPPH. ${ }^{\mathbf{T}} \mathrm{CDH}$ : conjugated diene hydroperoxide, mmol CDH

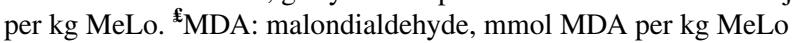

*Controls obtained under the same experimental group from two previous publications $[35,45]$ 
BHT $(0.11 \pm 0.01 \mathrm{~g}$ of antioxidant $/ \mathrm{mmol} \mathrm{DPPH}, p<0.05)$, if it is considered that they are crude extracts without an exhaustive purification process, they are considered quite good. In addition, the benefits of using plant extracts rich in polyphenols in dermocosmetics have been reported, not only for their antioxidant capacity but also for their anti-inflammatory, immunomodulant, photoprotective, and anti-cancer effects [23, 27, 46-48]. Concerning the results obtained in the lipid model, we observed that in the MeLo assay with BHT and each extract (assays 1-8), there was a protective effect both in the first stages of peroxidation, due to the absence of $\mathrm{CDH}$, as in the final stages due to a decrease in the formation of MDA with respect to MeLo without preserving. Additionally, the assays 2, 3, 5, and 7 did not show significant difference $(p<0.05)$ compared to BHT, concerning the inhibition of MDA formation. Therefore, an antioxidant capacity similar to BHT was demonstrated against the prevention of MeLo peroxidation.

Moreover, the analysis of variance for TPC assays showed that the interaction between solvent:acid:carbon was significant $(p=0.027)$. Furthermore, Fig. 1 shows that methanol as an extraction solvent and the addition of $\mathrm{HCl}$ increased the overall value of TPC. However, TPC values decrease when activated carbon is added due to the low selectivity of activated carbon that not only adsorbs chlorophylls but may also be absorbing other types of compounds, such as polyphenols, as previously reported in B. antioquensis extracts, a plant of the same family Asteraceae [45]. In previous studies carried out by us and various publications have shown that the addition of acids, mainly $\mathrm{HCl}$, increases the yield of polyphenol extraction [33, 45, 49, 50], as observed in this study (Table 2 tests $1,2,3$, and 4). The reason why we discarded the extracts where $\mathrm{HCl}$ was used was due to the poor sensory characteristics of these formulations, since the incorporation of these extracts was not adequate in the hydrogel, presenting brown colorations and large dispersed particles. This not only affects the characteristics of texture and color but also the effectiveness since there is not complete solubilization of the extract in the cosmetic matrix. Assays 1, 2, and 3 presented the highest TPC values, $(246.86 \pm 14.24,217.50 \pm 2.44,210.52 \pm 15.84$ EAG/g dry extract, respectively), among which there was no statistically significant difference. The other assays (4-8) presented values between $132.88 \pm 9.35$ and $171.39 \pm 7.80$ EAG/g dry extract, and did not present a statistically significant difference between them. Furthermore, we observed a high correlation between TPC and antioxidant activity $\left(R^{2}=0.7336\right)$.

Concerning the absorption capacity of the extracts in the UVA-UVB region, the analysis of variance showed that the interaction between the solvent, the acid, and the activated carbon was not significant $(p>0.05)$. In Fig. 2, the absorption coefficients of the extracts obtained in the different assays are shown, with a statistically
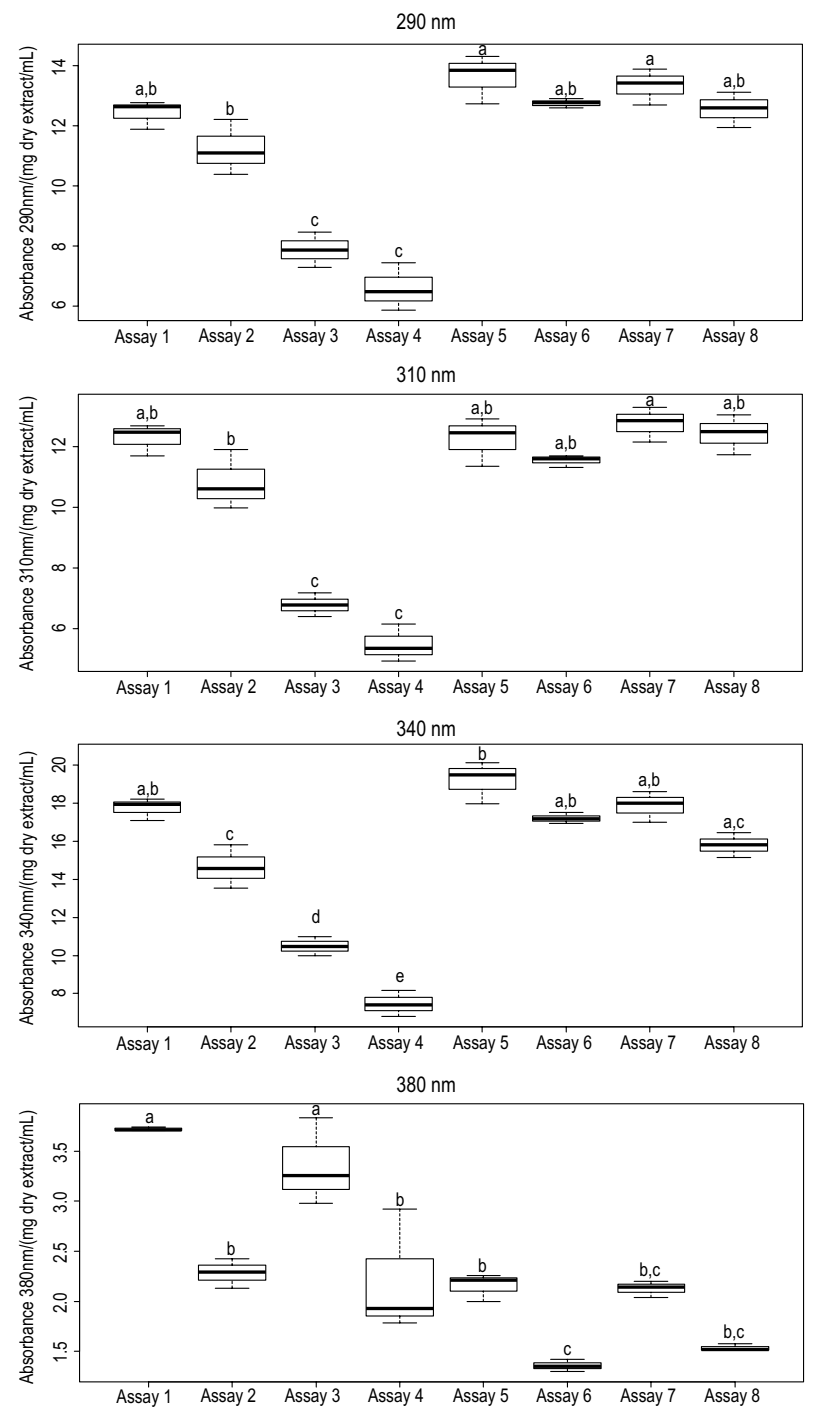

Fig. 2 UVA-UVB absorption coefficients of $P$. pulchella extracts. Data are the means of three replicates with standard deviation shown by vertical bars. Bars topped by different letters are significantly different at the 5\% level

non-significant reduction in the absorption coefficients in the presence of activated carbon (assays 2, 4, 6, and 8), for the tests without activated carbon (assays 1, 3, 5, and 7) for the absorption coefficients obtained at $290 \mathrm{~nm}$ and $310 \mathrm{~nm}$. On the other hand, there was significant differences between tests 1 and 2 and between 3 and 4 at $340 \mathrm{~nm}$, and between 1 and 2, 3 and 4, 5 and 6 at $380 \mathrm{~nm}$. These values decrease when activated carbon is added due to the low selectivity of activated carbon that not only adsorbs chlorophylls but may also be absorbing other types of compounds, such as polyphenols, that absorb at these wavelengths. Additionally, the reduction of the absorption coefficients was also notable when $\mathrm{HCl}$ was added. However, the solvent:carbon and acid:carbon interaction did 
Table 3 In vitro photoprotection and photostability of extracts of $P$. pulchella

\begin{tabular}{|c|c|c|c|c|c|c|c|}
\hline & & SPF & & APF & & $\overline{\lambda_{\mathrm{c}}}$ & UVA/UVB \\
\hline Gel & & $0.92 \pm 0.00$ & & 0.0 & & - & - \\
\hline CSS & SPF 25 & $25.18 \pm 1.11$ & & \pm 0.0 & & 56 & 0.430 \\
\hline Tim & $e, \min$ & 0 & 30 & 60 & 90 & 120 & $\begin{array}{c}\text { Gel spread on } \\
\text { paper }\end{array}$ \\
\hline & SPF & $6.3 \pm 0.1$ & $4.5 \pm 0.3$ & $4.0 \pm 0.2$ & $3.5 \pm 0.2$ & $3.3 \pm 0.1$ & \\
\hline & UVAPF & $5.0 \pm 0.0$ & - & - & - & $3.0 \pm 0.0$ & \\
\hline $\bar{z}$ & $\lambda_{\mathrm{c}}$ & 375 & 377 & 378 & 378 & 379 & \\
\hline 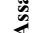 & UVA/UVB & 0.800 & 0.770 & 0.751 & 0.736 & 0.729 & \\
\hline & $\% \mathrm{SPF}_{\text {eff }}$ & $100.0 \%$ & $71.4 \%$ & $63.5 \%$ & $55.6 \%$ & $52.4 \%$ & \\
\hline & $\%$ UVAPF $_{\text {eff }}$ & $100.0 \%$ & - & - & - & $60.0 \%$ & \\
\hline & SPF & $4.8 \pm 0.4 \mathrm{a}$ & $4.0 \pm 0.2$ & $3.4 \pm 0.2$ & $3.0 \pm 0.1$ & $2.8 \pm 0.2$ & \\
\hline & UVAPF & $4.0 \pm 0.0$ & - & - & - & $2.0 \pm 0.0$ & \\
\hline$\stackrel{2}{z}$ & $\lambda_{\mathrm{c}}$ & 374 & 376 & 376 & 377 & 377 & \\
\hline$\frac{2}{2}$ & UVA/UVB & 0.794 & 0.756 & 0.733 & 0.718 & 0.711 & \\
\hline & $\% S P F_{\text {eff }}$ & $100.0 \%$ & $83.3 \%$ & $70.8 \%$ & $62.5 \%$ & $58.3 \%$ & \\
\hline & $\%$ UVAPF $_{\text {eff }}$ & $100.0 \%$ & - & - & - & $50.0 \%$ & \\
\hline & SPF & $3.4 \pm 0.2 \mathrm{~b}$ & $3.0 \pm 0.2$ & $2.9 \pm 0.2$ & $2.8 \pm 0.2$ & $2.7 \pm 0.2$ & \\
\hline & UVAPF & $3.0 \pm 0.0 \mathrm{a}$ & - & - & - & $2.3 \pm 0.6$ & \\
\hline 3 & $\lambda_{\mathrm{c}}$ & 380 & 381 & 381 & 382 & 382 & \\
\hline$\hat{z}$ & UVA/UVB & 0.843 & 0.822 & 0.816 & 0.809 & 0.800 & \\
\hline & $\% \mathrm{SPF}_{\text {eff }}$ & $100.0 \%$ & $88.2 \%$ & $85.3 \%$ & $82.4 \%$ & $79.4 \%$ & \\
\hline & $\% \mathrm{UVAPF}_{\text {eff }}$ & $100.0 \%$ & - & - & - & $76.7 \%$ & $=$ \\
\hline & SPF & $3.3 \pm 0.2 \mathrm{~b}$ & $3.0 \pm 0.2$ & $3.0 \pm 0.1$ & $3.0 \pm 0.1$ & $3.0 \pm 0.1$ & \\
\hline & UVAPF & $3.0 \pm 0.0 \mathrm{a}$ & - & - & - & $3.0 \pm 0.0$ & \\
\hline$\vec{z}$ & $\lambda_{\mathrm{c}}$ & 381 & 383 & 383 & 383 & 383 & \\
\hline$\frac{2}{4}$ & UVA/UVB & 0.808 & 0.821 & 0.820 & 0.814 & 0.810 & \\
\hline & $\% \mathrm{SPF}_{\text {eff }}$ & $100.0 \%$ & $90.9 \%$ & $90.9 \%$ & $90.9 \%$ & $90.9 \%$ & \\
\hline & $\%$ UVAPF $_{\text {eff }}$ & $100.0 \%$ & - & - & - & $100.0 \%$ & \\
\hline & SPF & $4.5 \pm 0.2 \mathrm{a}$ & $3.3 \pm 0.1$ & $3.1 \pm 0.1$ & $3.0 \pm 0.1$ & $3.0 \pm 0.2$ & \\
\hline & UVAPF & $3.7 \pm 0.6 \mathrm{a}$ & - & - & - & $2.3 \pm 0.6$ & \\
\hline 2 & $\lambda_{\mathrm{c}}$ & 375 & 376 & 377 & 377 & 377 & \\
\hline$\frac{2}{4}$ & UVA/UVB & 0.830 & 0.783 & 0.773 & 0.764 & 0.759 & \\
\hline & $\% \mathrm{SPF}_{\text {eff }}$ & $100.0 \%$ & $73.3 \%$ & $68.9 \%$ & $66.7 \%$ & $66.7 \%$ & \\
\hline & $\%$ UVAPF $_{\text {eff }}$ & $100.0 \%$ & - & - & - & $62.2 \%$ & \\
\hline & SPF & $3.0 \pm 0.1 \mathrm{~b}$ & $2.4 \pm 0.1$ & $2.3 \pm 0.1$ & $2.2 \pm 0.1$ & $2.2 \pm 0.1$ & \\
\hline & UVAPF & $3.0 \pm 0.0 \mathrm{a}$ & - & - & - & $2.0 \pm 0.0$ & \\
\hline 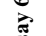 & $\lambda_{\mathrm{c}}$ & 374 & 375 & 375 & 375 & 375 & \\
\hline$\frac{2}{2}$ & UVA/UVB & 0.794 & 0.755 & 0.741 & 0.735 & 0.724 & \\
\hline & $\% \mathrm{SPF}_{\text {eff }}$ & $100.0 \%$ & $80.0 \%$ & $76.7 \%$ & $73.3 \%$ & $73.3 \%$ & \\
\hline & $\%$ UVAPF $_{\text {eff }}$ & $100.0 \%$ & - & - & - & $66.7 \%$ & \\
\hline & SPF & $7.3 \pm 0.9$ & $6.4 \pm 0.5$ & $5.2 \pm 0.5$ & $5.1 \pm 0.4$ & $4.9 \pm 0.5$ & \\
\hline & UVAPF & $5.3 \pm 0.6$ & - & - & - & $4.3 \pm 0.6$ & \\
\hline 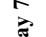 & $\lambda_{\mathrm{c}}$ & 376 & 379 & 379 & 379 & 379 & \\
\hline$\frac{5}{4}$ & UVA/UVB & 0.824 & 0.819 & 0.813 & 0.807 & 0.810 & \\
\hline & $\% \mathrm{SPF}_{\text {eff }}$ & $100.0 \%$ & $75.6 \%$ & $71.1 \%$ & $68.9 \%$ & $67.1 \%$ & \\
\hline & $\% \mathrm{UVAPF}_{\text {eff }}$ & $100.0 \%$ & - & - & - & $81.1 \%$ & \\
\hline & SPF & $3.4 \pm 0.2 \mathrm{~b}$ & $2.8 \pm 0.1$ & $2.7 \pm 0.1$ & $2.6 \pm 0.1$ & $2.5 \pm 0.2$ & \\
\hline & UVAPF & $3.0 \pm 0.0 \mathrm{a}$ & - & - & - & $2.0 \pm 0.0$ & \\
\hline$i_{i}^{\infty}$ & $\lambda_{\mathrm{c}}$ & 375 & 377 & 377 & 377 & 378 & \\
\hline$\frac{2}{2}$ & UVA/UVB & 0.793 & 0.787 & 0.783 & 0.780 & 0.777 & \\
\hline & $\% \mathrm{SPF}_{\text {eff }}$ & $100.0 \%$ & $82.4 \%$ & $79.4 \%$ & $76.5 \%$ & $73.5 \%$ & \\
\hline & $\% \mathrm{UVAPF}_{\text {eff }}$ & $100.0 \%$ & - & - & - & $66.7 \%$ & \\
\hline
\end{tabular}

Results are presented as the mean value $\pm \operatorname{SD}(n=3)$. Values for the same parameter followed by different letters have a statistically significant difference with a confidence level of $5 \%$. ${ }^{\dagger} \mathrm{CSS}$ : commercial sunscreen SPF 25, which contains $8.5 \%$ octocrylene, $7.0 \%$ ethylhexyl methoxycinnamate, $5.0 \%$ benzophenone-3, and $4.0 \%$ octyl salicylate as active ingredients not show a significant effect on the absorption coefficients $(p>0.05)$, contrary to the solvent:acid interaction where there was a significant effect $(p<0.05)$. Furthermore, no correlation was found between the TPC values and the absorption coefficients.

Regarding the preparation of gel formulations, there was difficulty in incorporating the extracts from trials 1 , 2,3 , and 4 . It was related to the addition of $\mathrm{HCl}$ in these extracts, which produced browned colored extracts, difficult to clean up with activated carbon. Moreover, they did not exhibit adequate sensory characteristics for topical use, which was much more evident in assays 1 and 2 (Images Table 3). These sensory properties are essential for cosmetic products, not only the efficiency and safety are relevant, characteristics, such as spreadability, texture perception, and visual appearance, among others, play a role in improving consumer acceptability. Therefore, because trials 1-4 did not meet the minimum sensory requirements, they were discarded.

On the other hand, the $\mathrm{pH}$ of the formulations where the extracts were incorporated was adjusted between 5.5 and 7.5 (suitable for topical formulations), and the amount of triethanolamine (TEA) added was that necessary to neutralize the carbomer (homopolymer of acrylic acid), in order to reach a $\mathrm{pH}$ close to 6-7, at which $\mathrm{pH}$ the polymer reaches its highest viscosity. Furthermore, additional base (TEA) was not necessary in the formulations where the extracts made with $\mathrm{HCl}$ were incorporated (assays 1-4), which indicates that the residual $\mathrm{HCl}$ in the extracts was not significant and only slightly decreased the $\mathrm{pH}$ values. Therefore, the $\mathrm{pH}$ of the formulations was measured and showed values between 5.9 and 6.6 (Base gel: 6.7, Gel assay 1: 6.1, Gel assay 2: 5.9, Gel assay 3: 6.3, Gel assay 4: 6.0, Gel assay 5: 6.4, Gel assay 6: 6.5, Gel assay 7: 6.5, Gel assay 8: 6.6).

The hydrogel formulations prepared with the extracts from tests 1-2 showed high SPF and UVAPF values (Table 3); these photoprotection effects are associated with high TPC values (Table 2) and absorption coefficients that contribute to efficacy (Fig. 2). However, the lack of solubility of the extracts affects the efficiency, since the large dispersed solid particles do not contribute significantly to the absorption of UVR, and on the contrary the contribution in the refraction and scattering of light is minimal. In addition, the particulate material in formulations 1-4 may be the reason for the poor correlation between the TPC and the $\operatorname{SPF}\left(R^{2}=0.3844\right)$ and the absorption coefficients at 290 , 310,340 , and $380 \mathrm{~nm}$ and $\operatorname{SPF}\left(R^{2}=0.0534, R^{2}=0.0107\right.$, $R^{2}=0.0278, R^{2}=0.6442$, respectively). Moreover, the variability in SPF values confirms the need for optimal selection 


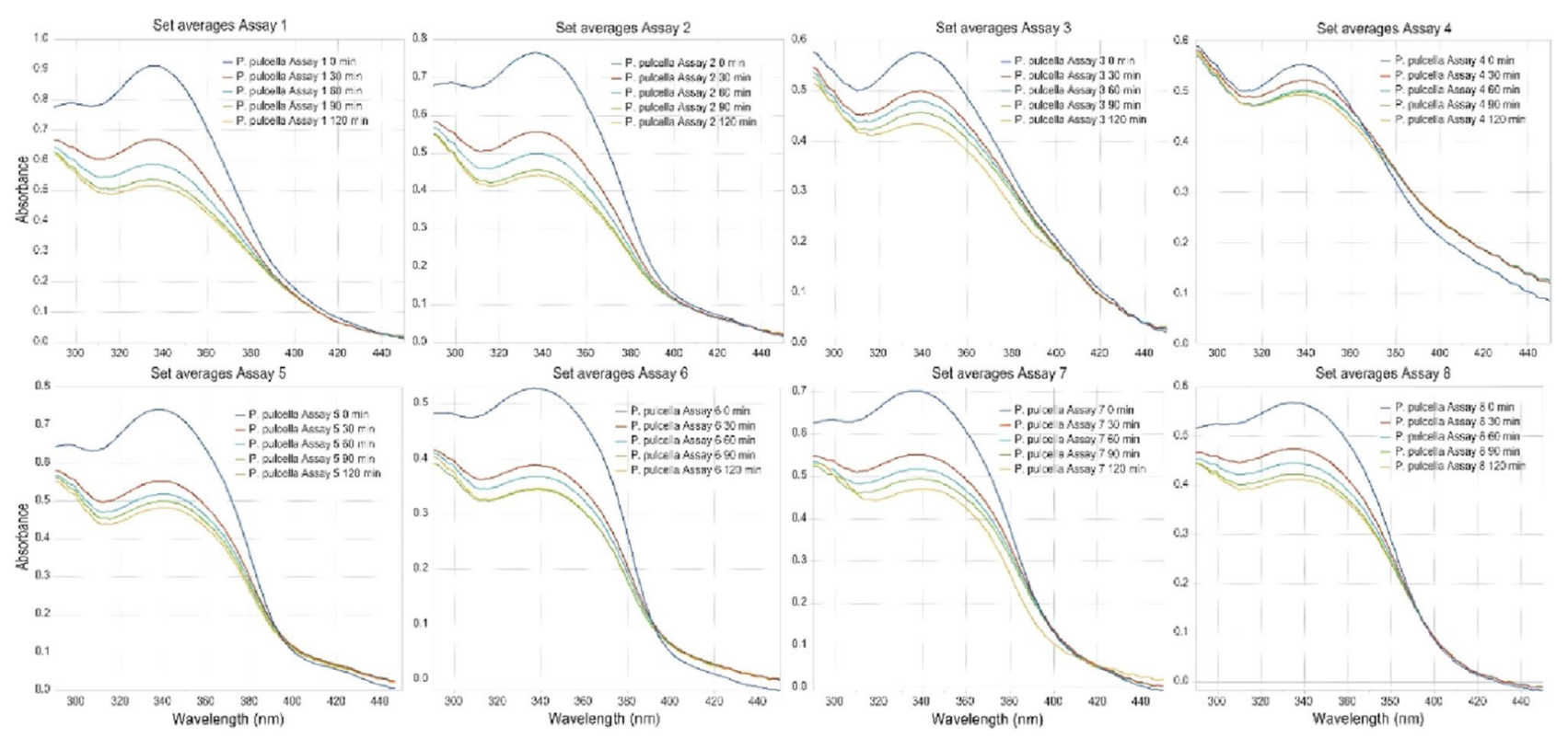

Fig. 3 Changes in the UVA-UVB spectra in the photostability study of the P. pulchella assays

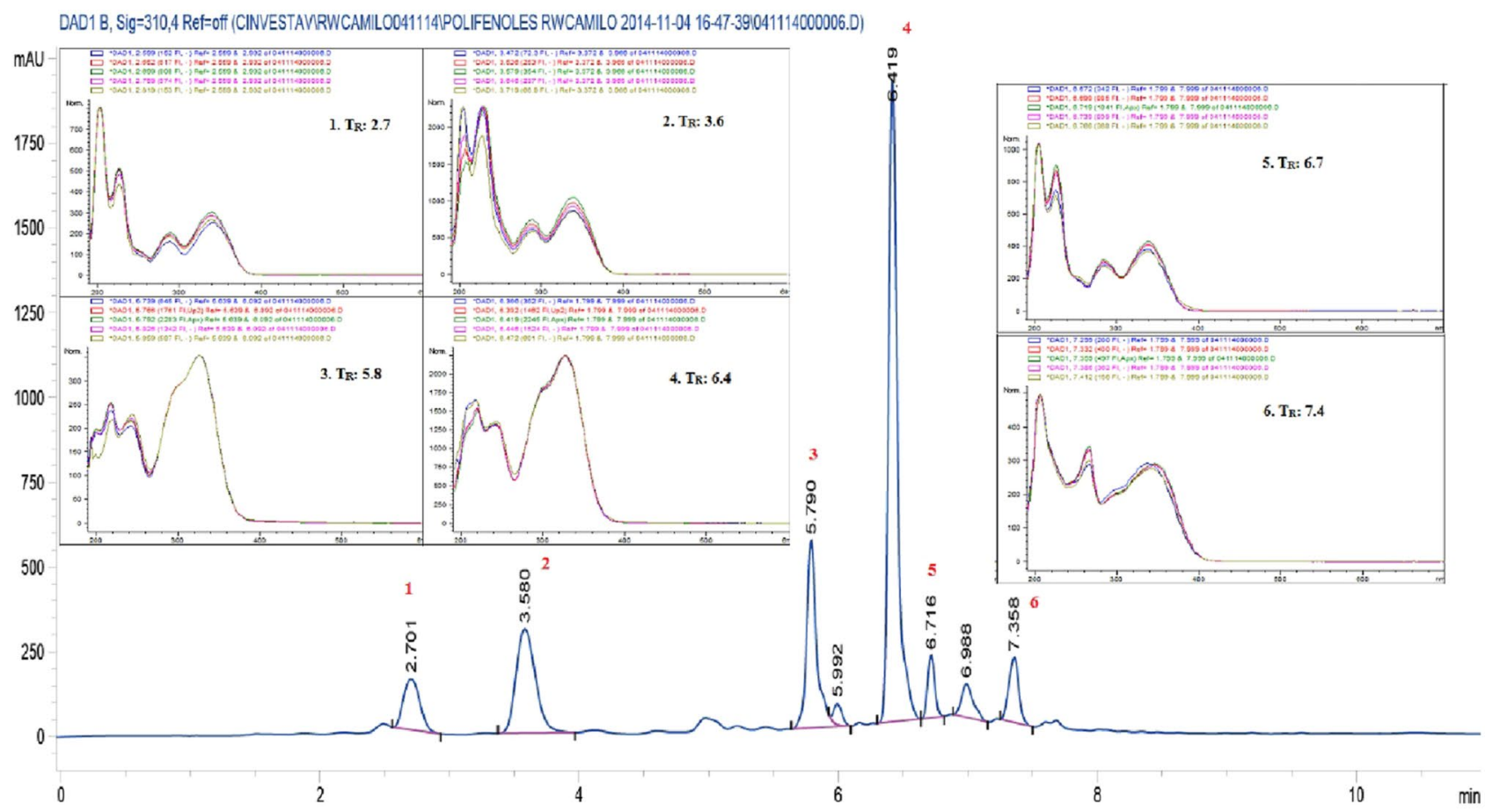

Fig. 4 HPLC-DAD chromatographic profile of the methanolic extract (assay 7) of P. pulchella

of the extract in the sunscreen formulation to minimize the effect of dispersed solid particles.

On the other hand, the gels containing the extracts from tests 5,6 , and 7 showed sensory characteristics according to a product for topical application (Images Table 3). Moreover, since assays 5-7 did not present dispersed solid particles, we can infer that the photoprotective effect (SPF and UVAPF) obtained on these formulations can be attributed to the polyphenolic compounds identified for $P$. pulchella with UVA-UVB absorption capability (Figs. 3 and 4).

In addition, the extracts of $P$. pulchella showed a broad spectrum in the UVA-UVB range, according to the 
European Commission, ISO, and FDA parameters [37, 51, 52]. All $\lambda_{\mathrm{c}}$ were higher than $370 \mathrm{~nm}$, and the UVAPF values were greater than one third of the SPF values, which allows declaring broad-spectrum UVB-UVA protection in the formulations (Table 3 ). In addition, the UVA/UVB ratio in assays $1,2,6$, and 8 were between 0.6 and 0.8 , which is equivalent to three stars $(\star \star \star)$ higher level of protection in the UVA range and for assays $3,4,5$, and 7 were $>0.8$, which is equivalent to four stars $(\star \star \star \star)$ maximum protection level, according to Boot's star rating system [53]. On the other hand, both the $\lambda_{\mathrm{c}}$ values and the UVA/UVB ratio for all the assays did not change significantly in the photostability study. In no case they were below $370 \mathrm{~nm}$ and 0.7 , respectively (Table 3) [52, 54, 55]. Table 3 and Fig. 3 show the results of the evaluation of the photostability of the extracts of $P$. pulchella in the gel formulations. Taking into account that for a formulation to be considered photostable, it must retain at least $80 \%$ of the effectiveness of the SPF and UVAPF (\% $\mathrm{SPF}_{\text {eff }}$ and $\left.\% \mathrm{UVAPF}_{\text {eff }}\right)$ after $2 \mathrm{~h}$ of irradiation [38, 42], it can be observed that the formulations 1,2 , $3,5,6$, and 8 were the most photo-unstable in both UVA and UVB with $\% \mathrm{SPF}_{\text {eff }}$ values between $52.4 \%$ and $79.4 \%$ and $\% \mathrm{UVAPF}_{\text {eff }}$ between $50.0 \%$ and $76.7 \%$, and formulation 7 presented instability in UVB, with a $\% \mathrm{SPF}_{\text {eff }}$ of $67.1 \%$ and a slight loss of efficacy in UVAPF with $\% \mathrm{UVAPF}_{\text {eff }}$ of 81.1\%. In Fig. 3, it can also be observed that the decrease in absorbance is another indication of the instability of these extracts in gel formulations. It was observed that the most photostable formulation was the one that contained the extract from assay $4\left(\% \mathrm{SPF}_{\text {eff }}=90.9 \%\right.$ and $\% \mathrm{UVAPF}-$ eff $100 \%$, Table 3 and Fig. 3). However, the values of SPF $(3.3 \pm 0.2)$ and UVAPF $(3.0 \pm 0.0)$ were not the highest compared to assays $1,2,5$, and 7 . Therefore, it was determined based on antioxidant activity, photoprotection, stability, and sensory characteristics (color, appearance, and texture), that the most promising extracts were those obtained in assays 5 and 7 . However, taking into account the percentage of extraction performance (assay $7=44.51 \pm 0.31 \%$, assay $5=22.84 \pm 0.53 \%)$ and the results of the photoprotection values in the UVA-UVB range (SPF: $7.3 \pm 0.9$, UVAPF: $5.3 \pm 0.6, \lambda_{\mathrm{c}} 376$ ), the formulation containing the extract from assay 7 was the most prominent.

For the identification of the main components of the methanol and acetone extracts of $P$. pulchella, an evaluation by HPLC-DAD and HPLC-ESI-MS ${ }^{n}$-IT was carried out. All the extracts (assays 1-8) presented similar chromatographic profiles; for this reason only the results and discussion of the data of the methanolic extract (assay 7) will be presented. Figure 4 shows the chromatographic profile obtained for the methanolic extract (assay 7) at a wavelength of $310 \mathrm{~nm}$ and Table 4 shows some spectroscopic characteristics of these compounds. Compound 2 retention time (RT) 3.6 (Supplementary Information, Fig. S2, Sch. S2) and compound 6 RT 7.4 (Supplementary Information, Fig. S6, Sch. S5) were identified as 3-O-caffeoylquinic acid (chlorogenic acid) and kaempferol 3-O-rhamnopyranosyl-( $1 \rightarrow 6)$-glucopyranoside,

Table 4 Spectral characteristics of the compounds identified in extract of $P$. pulchella

\begin{tabular}{|c|c|c|c|c|c|}
\hline Peak & $\mathrm{RT} \min$ & UV spectra $\lambda_{\max }(\mathrm{nm})$ & {$[\mathrm{M}+\mathrm{H}]^{+}$} & Major $\mathrm{MS}^{2}, \mathrm{MS}^{3}$, and $\mathrm{MS}^{4}$ fragments & Compound \\
\hline 1 & 2.7 & $203,227,288,339$ & 517 & $\begin{array}{l}\text { MS }^{2}: 517 \rightarrow 499,481,471,355,193 \\
\text { SS }^{3}: 355 \rightarrow 193,163 \\
\text { SS }^{4}: 193 \rightarrow 165,149,133 \\
\text { SS }^{4}: 163 \rightarrow 145,135,117\end{array}$ & Caffeoylquinic acid hexose \\
\hline 2 & 3.6 & $208,230,288,338$ & 355 & $\begin{array}{l}\mathrm{MS}^{2}: 355 \rightarrow 163 \\
\mathrm{MS}^{3}: 163 \rightarrow 145,135,117\end{array}$ & 3-O-caffeoylquinic acid (chlorogenic acid) \\
\hline 3 & 5.8 & $218,243,301$ sh, 326 & 523 & $\begin{array}{l}\text { MS }^{2}: 523 \rightarrow 505,487,343,193 \\
\text { SS }^{3}: 505 \rightarrow 487,193 \\
\text { MS }^{3}: 487 \rightarrow 469,343,325,297,193 \\
\text { MS }^{3}: 343 \rightarrow 315,297 \\
\text { MS }^{3}: 193 \rightarrow 178,165,133\end{array}$ & $\begin{array}{l}\text { Feruloyl maleate 4-O-8 (5,7-dihydroxy- } \\
\text { coniferyl alcohol) }\end{array}$ \\
\hline 4 & 6.4 & $220,242,303$ sh, 326 & 505,507 & $\begin{array}{l}\text {MS}^{2}: 505 \rightarrow 487,343,193 \\
\text { SS }^{2}: 507 \rightarrow 489,345,193 \\
\text { SS }^{3}: 487 \rightarrow 469,451,343,325,297,193 \\
\text { MS }^{3}: 343 \rightarrow 315,297 \\
\text { SS }^{3}: 193 \rightarrow 178,165,149,133\end{array}$ & $\begin{array}{l}\text { Feruloyl maleate 4-O-8- (7-hydroxy-coniferyl } \\
\text { alcohol) }\end{array}$ \\
\hline 5 & 6.7 & $206,226,284,339$ & 595 & $\begin{aligned} & \mathrm{MS}^{2}: 595 \rightarrow 433,287 \\
& \mathrm{MS}^{3}: 433 \rightarrow 287 \\
& \mathrm{MS}^{3}: 287 \rightarrow 269,259,241,213,165,153 \\
& 133,121\end{aligned}$ & $\begin{array}{l}\text { Kaempferol 3- } O \text {-glucopyrano- } \\
\text { syl-( }(1 \rightarrow 2) \text {-rhamnopyranose }\end{array}$ \\
\hline 6 & 7.4 & 206, 266, 299sh, 347 & 595 & $\begin{array}{l}\mathrm{MS}^{2}: 595 \rightarrow 449,433,287 \\
\mathrm{MS}^{3}: 449 \rightarrow 287 \\
\mathrm{MS}^{3}: 287 \rightarrow 269,259,241,213,165,153 \\
\quad 133,121\end{array}$ & $\begin{array}{l}\text { Kaempferol 3-O-rhamnopyrano- } \\
\text { syl-( }(\rightarrow 6) \text {-glucopyranose }\end{array}$ \\
\hline
\end{tabular}


respectively. These two compounds presented similar retention time and fragmentation patterns previously reported for the B. antioquensis plant (Asteraceae) [45].

Compound 1, with a RT of $2.7 \mathrm{~min}$ and a protonated molecular ion $[\mathrm{M}+\mathrm{H}]^{+}$at $\mathrm{m} / \mathrm{z} 517\left(\mathrm{MS}^{1}\right)$, presented a product ion of $\mathrm{m} / \mathrm{z} 355$ with the same spectral characteristics of compound 2 (chlorogenic acid) (Supplementary Information, Fig. S2, Sch. S2). According to these data, it was tentatively identified as caffeoylquinic acid hexose (chlorogenic acid-hexose), a compound previously reported (Supplementary Information, Fig. S1, Sch. S1) [56].

Compound 3, with a retention time of $5.8 \mathrm{~min}$ and a protonated molecular ion $[\mathrm{M}+\mathrm{H}]^{+}$at $\mathrm{m} / \mathrm{z} 523\left(\mathrm{MS}^{1}\right.$ ) (Supplementary Information, Fig. S3, Sch. S3), presented a product ion at $\mathrm{m} / \mathrm{z} 505$ with similar spectral characteristics to (feruloyl maleate 4-O-8-(7-hydroxy-coniferyl alcohol) (compound 4, RT 6.4) (Supplementary Information, Fig. S4, Sch. S3) and was tentatively identified as feruloyl maleate 4-O-8 (5,7-dihydroxy-coniferyl alcohol), due to biosynthetic evidence that coniferyl alcohol (phenylpropanoid derived from shikimic acid) may exhibit additional hydroxylation at position 5. This fact is confirmed since the fragments of the feruloyl maleate portion presented an identical fragmentation pattern to feruloyl maleate 4-O-8-(7-hydroxyconiferyl alcohol). In this sense, Rohde A. et al. (2004) [57], in a metabolomic study of phenylpropanoids carried out in Arabidopsis thaliana by $\mathrm{MS}^{\mathrm{n}}$ in negative mode, reported feruloyl maleate coupled 4-O-8 to coniferyl alcohol with $\mathrm{MS}^{1} \mathrm{~m} / \mathrm{z} 505, \mathrm{MS}^{2} \mathrm{~m} / \mathrm{z} 389$, and $\mathrm{MS}^{3} \mathrm{~m} / \mathrm{z} 341$, and 193 , compared to standard.

Compound 5, with a retention time of $6.7 \mathrm{~min}$, was identified as kaempferol 3-O-glucopyranosyl-(1 $\rightarrow \mathbf{2})$-rhamnopyranose (Supplementary Information, Fig. S5, Sch. S4), and its spectral characteristics differ significantly from compound 6, which presented the same molecular ion and was identified as kaempferol 3-O-rhamnopyranosyl-(1 $\rightarrow$ 6)-glucopyranose (RT $7.4 \mathrm{~min}$ ) (Supplementary Information, Fig. S6, Sch. S5) since, in the experiment $\mathrm{MS}^{2}$ from $\mathrm{m} / \mathrm{z} 595$, the initial loss of rhamnose $\left(\mathrm{Y}_{1}{ }^{+} \mathrm{m} / \mathrm{z} 449\right)$ was not observed. Still, instead, the loss of glucose $\left(\mathrm{Y}_{1}{ }^{+} \mathrm{m} / \mathrm{z}\right.$ 433) was initially presented and then the loss of rhamnose, without observing the characteristic ion $\mathrm{Y}^{*}$ of diglycosides with interglycosidic bond $1 \rightarrow 6$. To determine the type of interglycosidic union $(1 \rightarrow 6$ or $1 \rightarrow 2)$ in the sugar residue, two spectral facts were taken into account that have been reported by Cuyckens and Claeys [58], that confirm the union $1 \rightarrow 2$. First, the proportion of the $\mathrm{Y}_{1}{ }^{+} / \mathrm{Y}_{0}{ }^{+}$ions is lower in the $1 \rightarrow 6$ junctions. The second, much more significant fact is the absence of the $\mathrm{Y}^{*}$ ion $(\mathrm{m} / \mathrm{z} 449)$, which would correspond to the loss of internal sugar, in this case, rhamnose, to produce by rearrangement an aglycone $O$-glucose ion. This rearrangement has been reported as characteristic of di-glycosylated flavonoids with $1 \rightarrow 6$ bonding, but not for $1 \rightarrow 2$ interglycosidic bonds. In addition, the $\mathrm{Y}_{0}^{+}$ ion at m/z 287 (Supplementary Information, Fig. S5, and S6, Sch. S4 and S5) was identified as kaempferol compared to standard with the same fragmentation pattern described for kaempferol 3-O-ramnopyranosyl-( $1 \rightarrow 6)$-glucopyranose from $B$. antioquensis [45].

The characterization of the extracts of $P$. pulchella showed that all the identified compounds are structurally phenylpropanoids derived from hydroxycinnamic acid with a C6-C3 skeleton, such as caffeic acid and ferulic acid (compounds 1, 2, 3, and 4), as well as flavonoids derived from chalcone, with a characteristic skeleton in their structure C6-C3-C6, like Kaempferol (compounds 5 and 6). In this sense, C6-C3 compounds, such as hydroxycinnamic acid derivatives ( $p$-coumaric acid, ferulic acid, caffeic acid, etc.) have been reported as good attenuators of UVB radiation, with $\varepsilon_{\max }$ in the 310-325-nm waveband. Likewise, the majority of flavonoids (i.e., apigenin, luteolin, quercetin, kaempferol, etc.) present absorption bands in the UVA-UVB between 280 and $355 \mathrm{~nm}$, allowing characteristics of a wide spectrum of protection [11, 12, 16, 27, 30, 40, 46, 48]. In addition, currently one of the most used filters in sunscreen preparations on the market, due to its protective effect on UVB, in addition to its stability is Ethylhexyl Methoxycinnamate (INCI name) or Octinoxate (USAN name), authorized by the European Commission and FDA. For this reason, the compounds present in the extracts of $P$. pulchella are recognized in the literature as defense metabolites of plants against the harmful effects of UVA-UVB radiation, since they can act as solar filters and as substances with high antioxidant activity, which was confirmed by the efficacy tests carried out in this study.

\section{Conclusion}

On basis of the antioxidant activity, photoprotection, stability, sensory characteristics (color, appearance, and texture), and yield percentage of extraction, the extract identified as assay 7 (acid-free $\mathrm{MeOH}$ extract and without treatment with activated charcoal) was identified as the most promising extract of $P$. pulchella. It demonstrates a remarkable antioxidant and broad photoprotective capacity, complying with the requirements of the European Commission, ISO, and FDA. This was also supported by identifying secondary metabolites present in the extracts, and their polyphenolic structural characteristics, with chromophore groups capable of absorbing UVR in the UVA-UVB region and with free radical scavenger and antioxidant properties. Although more studies are needed to improve the photostability of formulations, for example, through the use of micro- and nanoencapsulation and quenching mechanisms, our findings 
suggest $P$. pulchella plant as source of potential natural UV filters and antioxidants for skin protection.

Electronic supplementary material The online version of this article (https://doi.org/10.1007/s43630-021-00120-z) contains supplementary material, which is available to authorized users.

Acknowledgements JC Mejía-Giraldo acknowledges doctoral fellowship granted by Colciencias (National Research Council). This work was supported by CODI-University of Antioquia (Project no. IN632CE) and the grant Conacyt-DFG 2016/277850.

Author contributions JCM-G conceived and performed the experiments, analyzed the data, and drafted the paper. RW revised and edited the paper. MAP-M supervised the experiments, revised the paper, and gave the final approval of the manuscript and funding acquisition. All the authors read and approved the manuscript as submitted.

Funding This study was funded by CODI-Universidad de Antioquia (Proyecto N ${ }^{\circ}$ IN632CE) and the grant Conacyt-DFG 2016/277850. Juan C. Mejía-Giraldo received a doctoral scholarship by Colciencias (National Research Council).

\section{Declarations}

Conflict of interest The authors declare that they have no conflict of interest among them or with the parent institution.

Data availability Not applicable.

Code availability Not applicable.

\section{References}

1. Simões, M. C. F., Sousa, J. J. S., \& Pais, A. A. C. C. (2015). Skin cancer and new treatment perspectives: a review. Cancer Letters, 357, 8-42. https://doi.org/10.1016/j.canlet.2014.11.001

2. Gilaberte, Y., \& González, S. (2010). Update on photoprotection. Actas Dermo-Sifiliográficas, 101, 659-672. https://doi.org/10. 1016/S1578-2190(10)70696-X

3. Seité, S., Moyal, D., Verdier, M.-P., Hourseau, C., \& Fourtanier, A. (2000). Accumulated p53 protein and UVA protection level of sunscreens. Photodermatology, Photoimmunology and Photomedicine, 16, 3-9. https://doi.org/10.1034/j.1600-0781.2000. 160103.x

4. de Gruijl, F. R. (1999). Skin cancer and solar UV radiation. European Journal of Cancer, 35, 2003-2009. https://doi.org/10.1016/ S0959-8049(99)00283-X

5. Halliday, G. M., Byrne, S. N., Kuchel, J. M., Poon, T. S. C., \& Barnetson, R. S. C. (2004). The suppression of immunity by ultraviolet radiation: UVA, nitric oxide and DNA damage. Photochemical \& Photobiological Sciences, 3, 736-740. https://doi. org/10.1039/B313199H

6. Pinnell, S. R. (2003). Cutaneous photodamage, oxidative stress, and topical antioxidant protection. Journal of the American Academy of Dermatology, 48, 1-19. https://doi.org/10.1067/mjd.2003. 16 Quiz 20-2.

7. Khan, T., Date, A., Chawda, H., \& Patel, K. (2019). Polysaccharides as potential anticancer agents-a review of their progress. Carbohydrate Polymers, 210, 412-428. https://doi.org/10.1016/j. carbpol.2019.01.064
8. Carrasco-Ríos, L. (2009). Efecto de la radiación ultravioleta-B en plantas. Idesia (Arica), 27, 59-76. https://doi.org/10.4067/S071834292009000300009

9. Agati, G., Galardi, C., Gravano, E., Romani, A., Applicata, F., Nazionale, C., Infm, S., \& Tattini, M. (2002). Flavonoid distribution in tissues of Phillyrea latifolia L. leaves as estimated by microspectrofluorometry and multispectral fluorescence microimaging. Photochemistry and Photobiology, 76, 350-360.

10. Zu, Y., Pang, H.-H., Yu, J.-H., Li, D.-W., Wei, X.-X., Gao, Y.-X., \& Tong, L. (2010). Responses in the morphology, physiology and biochemistry of Taxus chinensis var mairei grown under supplementary UV-B radiation. The Journal of Photochemistry and Photobiology B: Biology, 98, 152-158. https://doi.org/10.1016/j. jphotobiol.2009.12.001

11. Agati, G., \& Tattini, M. (2010). Multiple functional roles of flavonoids in photoprotection. New Phytologist, 186, 786-793. https:// doi.org/10.1111/j.1469-8137.2010.03269.x

12. Agati, G., Brunetti, C., Di Ferdinando, M., Ferrini, F., Pollastri, S., \& Tattini, M. (2013). Functional roles of flavonoids in photoprotection: new evidence, lessons from the past. Plant Physiology and Biochemistry, 72, 35-45. https://doi.org/10.1016/j.plaphy.2013. 03.014

13. Quattrocchio, F., Baudry, A., Lepiniec, L., \& Grotewold, E. (2006). The regulation of flavonoid biosynthesis. In E. Grotewold (Ed.), The science of flavonoids $S E-4$ (pp. 97-122). Springer. https://doi.org/10.1007/978-0-387-28822-2_4

14. Winkel-Shirley, B. (2002). Biosynthesis of flavonoids and effects of stress. Current Opinion in Plant Biology, 5, 218-223. https:// doi.org/10.1016/S1369-5266(02)00256-X

15. Agati, G., Biricolti, S., Guidi, L., Ferrini, F., Fini, A., \& Tattini, M. (2011). The biosynthesis of flavonoids is enhanced similarly by UV radiation and root zone salinity in L. vulgare leaves. Journal of Plant Physiology, 168, 204-212. https://doi.org/10.1016/j. jplph.2010.07.016

16. Guidi, L., Brunetti, C., Fini, A., Agati, G., Ferrini, F., Gori, A., \& Tattini, M. (2016). UV radiation promotes flavonoid biosynthesis, while negatively affecting the biosynthesis and the deepoxidation of xanthophylls: Consequence for photoprotection? Environmental and Experimental Botany, 127, 14-25. https:// doi.org/10.1016/j.envexpbot.2016.03.002

17. Mejía-Giraldo, J. C., Atehortúa, L., \& Puertas-Mejía, M. Á. (2014). Foto-protección: mecanismos bioquímicos, punto de partida hacia mejores filtros solares. Dermatología Cosmética, Médica y Quirúrgica, 12, 272-281.

18. F'guyer, S., Afaq, F., \& Mukhtar, H. (2003). Photochemoprevention of skin cancer by botanical agents. Photodermatology, Photoimmunology and Photomedicine, 19, 56-72. https://doi. org/10.1034/j.1600-0781.2003.00019.x

19. Stahl, W., \& Sies, H. (2005). Bioactivity and protective effects of natural carotenoids. Biochimica et Biophysica Acta, 1740, 101-107. https://doi.org/10.1016/j.bbadis.2004.12.006

20. Whitehead, K., \& Hedges, J. I. (2005). Photodegradation and photosensitization of mycosporine-like amino acids. Journal of Photochemistry and Photobiology B: Biology, 80, 115-121. https://doi.org/10.1016/j.jphotobiol.2005.03.008

21. Edreva, A. (2005). The importance of non-photosynthetic pigments and cinnamic acid derivatives in photoprotection. Agriculture, Ecosystems and Environment, 106, 135-146. https:// doi.org/10.1016/j.agee.2004.10.002

22. Verschooten, L., Claerhout, S., Laethemii, A. V., Agostinis, P., \& Garmyn, M. (2006). New strategies of photoprotection. Photochemistry and Photobiology, 82, 1016-1023.

23. Svobodová, A., Psotová, J., \& Walterová, D. (2003). Natural phenolics in the prevention of UV-induced skin damage. A review. Biomedical Paper, 147, 137-145. https://doi.org/10. 5507/bp.2003.019 
24. Katiyar, S. K., Perez, A., \& Mukhtar, H. (2000). Green tea polyphenol treatment to human skin prevents formation of ultraviolet light B-induced pyrimidine dimers in DNA. Clinical Cancer Research, 6, 3864-3869.

25. Zaid, M. A., Afaq, F., Syed, D. N., \& Mukhtar, H. (2009). Chapter 8-botanical antioxidants for protection against damage from sunlight. In A. Tabor \& R. M. C. Blair (Eds.), Personal care and cosmetic technology (pp. 161-183). William Andrew Publishing. https://doi.org/10.1016/B978-0-8155-2029-0.50015-6

26. Yamaguchi, L. F., Vassão, D. G., Kato, M. J., \& Di Mascio, P. (2005). Biflavonoids from Brazilian pine Araucaria angustifolia as potentials protective agents against DNA damage and lipoperoxidation. Phytochemistry, 66, 2238-2247. https://doi.org/10. 1016/j.phytochem.2004.11.014

27. Masaki, H. (2010). Role of antioxidants in the skin: anti-aging effects. Journal of Dermatological Science, 58, 85-90. https:// doi.org/10.1016/j.jdermsci.2010.03.003

28. Monsalve-Bustamante, Y. A. Y. A., Puertas-Mejia, M. A. M. A., \& Mejia-Giraldo, J. C. J. C. (2020). Comparison of the photoprotective effect between hydrolyzed and aglycones flavonoids as sunscreen: a systematic review. Journal of Applied Pharmaceutical Science, 10, 116-123. https://doi.org/10.7324/japs. 2020.101016

29. Harbaum, B., Hubbermann, E. M. E., Wolff, C., Herges, R., Zhu, Z., \& Schwarz, K. (2007). Identification of flavonoids and hydroxycinnamic acids in pak choi varieties (Brassica campestris L. ssp. chinensis var. communis) by HPLC-ESI-MSn and NMR and their quantification by HPLC-DAD. Journal of Agriculture and Food Chemistry, 55, 8251-8260.

30. Velasco, M. V. R., Sarruf, F. D., Salgado-Santos, I. M. N., Haroutiounian-Filho, C. A., Kaneko, T. M., \& Baby, A. R. (2008). Broad spectrum bioactive sunscreens. International Journal of Pharmaceutics, 363, 50-57. https://doi.org/10.1016/j.ijpharm.2008.06. 031

31. Brand-Williams, W., Cuvelier, M. E., \& Berset, C. (1995). Use of a free radical method to evaluate antioxidant activity. $L W T$ Food Science and Technology, 28, 25-30. https://doi.org/10.1016/ S0023-6438(95)80008-5

32. Puertas-Mejía, M. A. M. A., Gutierrez-villegas, M. I. M. I., Mejíagiraldo, J. C. J. C., Winkler, R., \& Rojano, B. (2018). In vitro UV absorption properties and radical scavenging capacity of Morella parvifolia (Benth.) Parra-Os. extracts. Brazilian Journal of Pharmaceutical Sciences, 54, 1-8. https://doi.org/10.1590/ s2175-97902018000317498

33. Mejía-giraldo, J. C., Gallardo, C., \& Puertas-mejía, M. A. (2015). In vitro photoprotection and antioxidant capacity of Sphagnum meridense extracts, a novel source of natural sunscreen from the mountains of Colombia. De Gruyter, 87, 961-970. https://doi.org/ 10.1515/pac-2015-0302

34. Wolfe, K., Wu, X., \& Liu, R. H. (2003). Antioxidant activity of apple peels. Journal of Agriculture and Food Chemistry, 51, 609-614. https://doi.org/10.1021/jf020782a

35. Mejía-Giraldo, J. C., Henao-Zuluaga, K., Gallardo, C., Atehortúa, L., \& Puertas-Mejía, M. A. (2016). Novel in vitro antioxidant and photoprotection capacity of plants from high altitude ecosystems of Colombia. Photochemistry and Photobiology, 92, 150-157. https://doi.org/10.1111/php.12543

36. Puertas-Mejía, M. A. M. A., Rincón-Valencia, S., \& Mejíagiraldo, J. C. J. C. (2015). Screening of UVA/UVB absorption and in vitro antioxidant capacity of Bejaria aestuans, Cavendishia pubescens and Cavendishia bracteata leaf extracts. Research Journal of Medicinal Plant, 9, 435-441. https://doi.org/10.3923/ rjmp. 2015
37. International Organization for Stardatization, (2012). ISO 24443:2012. Determination of sunscreen UVA photoprotection in vitro. 31

38. Moyal, D., Alard, V., Bertin, C., Boyer, F., Brown, M. W., Kolbe, L., Matts, P., \& Pissavini, M. (2013). The revised COLIPA in vitro UVA method. International Journal of Cosmetic Science, 35, 35-40. https://doi.org/10.1111/j.1468-2494.2012.00748.x

39. Jarzycka, A., Lewińska, A., Gancarz, R., \& Wilk, K. A. (2013). Assessment of extracts of Helichrysum arenarium, Crataegus monogyna, Sambucus nigra in photoprotective UVA and UVB; photostability in cosmetic emulsions. Journal of Photochemistry and Photobiology B: Biology, 128, 50-57. https://doi.org/10. 1016/j.jphotobiol.2013.07.029

40. Choquenet, B., Couteau, C., Paparis, E., \& Coiffard, L. J. M. (2008). Quercetin and rutin as potential sunscreen agents: determination of efficacy by an in vitro method. Journal of Natural Products, 71, 1117-1118. https://doi.org/10.1021/np7007297

41. Vicentini, F. T. M. C., Georgetti, S. R., Jabor, J. R., Caris, J. A., Bentley, M. V. L. B., \& Fonseca, M. J. V. (2007). Photostability of quercetin under exposure to UV irradiation. Latin American Journal of Pharmacy, 26, 119-124.

42. Hojerová, J., Medovcíková, A., \& Mikula, M. (2011). Photoprotective efficacy and photostability of fifteen sunscreen products having the same label SPF subjected to natural sunlight. International Journal of Pharmaceutics, 408, 27-38. https://doi.org/10. 1016/j.ijpharm.2011.01.040

43. Marque, C., Pensé-Lhéritier, A.-M., \& Bacle, I. (2022). Sensory methods for cosmetics evaluation. Nonfood Sesory Practices. https://doi.org/10.1016/B978-0-12-821939-3.00012-9

44. Mérat, E., Roso, A., Dumaine, M., \& Sigurani, S. (2022). Sensory evaluation of cosmetic functional ingredients. Nonfood Sesory Practices. https://doi.org/10.1016/B978-0-12-821939-3.00018-X

45. Mejía-Giraldo, J. C., Winkler, R., Gallardo, C., Sánchez-Zapata, A. M., \& Puertas-Mejía, M. A. (2016). Photoprotective Potential of Baccharis antioquensis (Asteraceae) as natural sunscreen. Photochemistry and Photobiology, 92, 742-752. https://doi.org/ 10.1111/php.12619

46. Articles, C., Katiyar, S. K., Perez, A., \& Mukhtar, H. (2000). Green tea polyphenol treatment to human skin prevents formation of ultraviolet light B-induced pyrimidine dimers in DNA. Clinical Cancer Research, 6, 3864-3869.

47. Anitha, T. (2012). Medicinal plants used in skin protection. Asian Journal of Pharmaceutical and Clinical Research, 5, 3-6.

48. Balakrishnan, K. P., Narayanaswamy, N., Itc, R., Industrial, P., $\&$ Phase, A. (2011). Botanicals as sunscreens: their role in the prevention of photoaging and skin cancer. International Journal of Cosmetic Science, 1, 13-16.

49. Kajdžanoska, M., Petreska, J., \& Stefova, M. (2011). Comparison of different extraction solvent mixtures for characterization of phenolic compounds in strawberries. Journal of Agriculture and Food Chemistry, 59, 5272-5278. https://doi.org/10.1021/jf2007826

50. Naczk, M., \& Shahidi, F. (2004). Extraction and analysis of phenolics in food. Journal of Chromatography A, 1054, 95-111. https://doi.org/10.1016/j.chroma.2004.08.059

51. COLIPA. (2011). Method for In Vitro Determination of UVA Protection (European Cosmetic, Toiletry and Perfumery Association). In vitro method for the determination of the UVA protection factor and "critical wavelength" values of sunscreen products, guidelines

52. Department of Health and Human Service. Food and Drug Administration. (2011). Over-the-counter sunscreen drug products; required labeling based on effectiveness testing. CFR 21 part 201.327. https://doi.org/10.1017/CBO9781107415324.004 
53. Boots the Chemist Ltd. (2008). The revised guidelines to the practical measurement of UVA/UVB ratios according to the Boots star rating system. The Boots Co., PLC.

54. Padera, F. (2011). Sunscreen testing according to COLIPA 2011/ FDA final rule 2011 using UV/Vis LAMBDA spectrophotometers (pp. 1-9). PerkinElmer Inc.

55. COLIPA. (2011). In vitro method for the determination of the UVA protection factor and "critical wavelength" values of sunscreen products: guideline. European Cosmetic, Toiletry and Perfumery Association

56. Ma, C., Whitaker, B. D., \& Kennelly, E. J. (2010). New 5-O-caffeoylquinic acid derivatives in fruit of the wild eggplant relative Solanum viarum. Journal of Agriculture and Food Chemistry, 58, 11036-11042. https://doi.org/10.1021/jf102963f

57. Rohde, A., Morreel, K., Ralph, J., Goeminne, G., Hostyn, V., De Rycke, R., Kushnir, S., Van Doorsselaere, J., Joseleau, J.-P., Vuylsteke, M., Van Driessche, G., Van Beeumen, J., Messens, E., \& Boerjan, W. (2004). Molecular phenotyping of the pal1 and pal2 mutants of Arabidopsis thaliana reveals far-reaching consequences on phenylpropanoid, amino acid, and carbohydrate metabolism. The Plant Cell, 16, 2749-2771.

58. Cuyckens, F., \& Claeys, M. (2004). Mass spectrometry in the structural analysis of flavonoids. Journal of Mass Spectrometry, 39, 1-15. https://doi.org/10.1002/jms.585 